\title{
Gravidez, parto e puerpério na pandemia: os múltiplos sentidos do risco
}

\section{Pregnancy, childbirth and postpartum in the pandemic: the multiple meanings of risk}

\author{
Fernanda Loureiro Silva' \\ https://orcid.org/0000-0002-5520-4647 \\ fernandaloureirosilva@gmail.com \\ Jane Russo' \\ https://orcid.org/0000-0002-4383-334X \\ jane.russo@gmail.com \\ Marina Nuccil \\ https://orcid.org/0000-0003-3465-9201 \\ marinanucci@gmail.com \\ ' Universidade do Estado do Rio de Janeiro - Rio de Janeiro, RJ, Brasil
}




\title{
Resumo
}

No Brasil, diferentemente de outros países afetados pela pandemia de Covid-19, mulheres grávidas e puérperas foram logo de início incluídas nos grupos de risco para a nova doença. Esse fato teve grande repercussão no movimento de humanização do parto no país. Neste artigo, analisamos os argumentos favoráveis a essa inclusão no debate on-line entre ativistas pelo parto humanizado, assim como as possíveis mudanças impulsionadas pelas noções de risco que essa pandemia traz para a cena do parto. A partir de uma leitura antropológica sobre a construção do risco na gravidez e no nascimento, argumentamos que três sentidos de risco são evocados: a vulnerabilidade dos corpos de mulheres grávidas e puérperas; a noção de contágio; e o problema da mortalidade materna. Buscamos também tecer reflexões sobre os paradoxos e tensões que a caracterização como "grupo de risco" pode representar para a assistência humanizada e para a vida reprodutiva das mulheres brasileiras.

Palavras-chave: risco; Covid-19; gravidez; parto humanizado.

\begin{abstract}
In Brazil, unlike other countries affected by the COVID-19 pandemic, pregnant women and women who have recently given birth were included in risk groups for the new disease. This fact had great impact into the Brazilian childbirth humanization movement. In this article, we examine the online debate among activists to understand the favorable arguments to this inclusion, as well as change proposals driven by notions of risk that this pandemic brings to the delivery scene. From an anthropological perspective on the risk construction in pregnancy and childbirth, three different meanings of risk were evoked: the vulnerability of the pregnant/postpartum bodies; the notion of contagion; and maternal mortality. We also seek to weave some reflections on the paradoxes and strains that the "risk group" labeling can represent for humanized healthcare and for the reproductive matters of Brazilian women.
\end{abstract}

Keywords: risk; COVID-19; pregnancy; natural childbirth. 


\section{Introdução}

Um mês após a Organização Mundial da Saúde (OMS) declarar a pandemia provocada pelo novo coronavírus, mulheres grávidas, puérperas e após abortamento passaram a ser consideradas "grupo de risco" para Covid-19 no Brasil. Chamou-nos atenção o fato de ativistas ligadas ao parto humanizado terem exaltado essa inclusão. Afinal, fazer parte de um grupo de risco, sobretudo no caso dessa nova doença, seria motivo para inquietação e angústia. Passamos então a coletar posts de ativistas em redes sociais para compreender suas perspectivas. Nossa atenção voltou-se para a repercussão de novas diretrizes no "movimento de humanização do parto" (MH), examinando, de forma exploratória, como o perigo de contágio pelo novo coronavírus poderia impactar a proposta do "parto humanizado".

Neste trabalho pretendemos discutir a forma como a caracterização de grávidas e puérperas como "grupo de risco" se articula com propostas de (re)definição das práticas de pré-natal e assistência ao parto. Em nossa discussão buscaremos apontar as articulações entre essas práticas e os múltiplos sentidos de risco que a pandemia evoca, bem como apresentar reflexões - preliminares e, possivelmente, transitórias - acerca das tensões que essa "rotulagem de risco" pode representar para a assistência humanizada e para as experiências reprodutivas de mulheres brasileiras.

Cabe ressaltar que o MH é múltiplo e polissêmico (Carneiro, 2015; Diniz, 2005), sendo formado por profissionais de diversas áreas, além de mulheres e parceiros/as simpatizantes das reivindicações que estruturam o ideário do movimento. O MH vem promovendo, há pelo menos duas décadas, encontros e debates entre ativistas de diversas partes do Brasil através da internet: inicialmente, utilizando as já obsoletas "listas de discussão", como a lista "Parto Natural" (Jones, 2015), e atualmente, através de grupos, páginas e perfis nas redes sociais Facebook e Instagram. Com o início da pandemia, o uso desses espaços como forma de apresentar reivindicações associadas ao movimento e divulgar informações sobre a nova doença foi intensificado. ${ }^{1}$ Como mencionamos

1 As restrições de contato fizeram com que as consultas com doulas, "rodas de gestantes" e outros encontros promovidos pelo $\mathrm{MH}$ fossem transferidos para o ambiente virtual. 
em trabalho anterior (Russo et al., 2019), acreditamos que tais informações e reivindicações compõem um mosaico de ideias, opiniões e relatos, através dos quais é possível fazer uma espécie de imersão no MH e reunir material para fundamentar os argumentos aqui apresentados.

Assim, para esta análise, concentramos nossa observação nos perfis de algumas profissionais da "assistência humanizada", especialmente de doulas, médicas e enfermeiras. Entre elas, focamos especialmente nas publicações e lives de uma médica e uma enfermeira obstétrica que compõem o Grupo Brasileiro de Estudos de Covid-19 e Gravidez (GBECG), ${ }^{2}$ protagonista na divulgação de informações sobre Covid-19 dentro do MH. Além disso, coletamos publicações de organizações da sociedade civil, como a rede Parto do Princípio, a Rede pela Humanização do Parto e Nascimento (ReHuNa), o coletivo de advogadas Nascer Direito e as associações de doulas (nacional e regionais), atores centrais nas reivindicações para a manutenção dos direitos das grávidas, parturientes e puérperas durante a pandemia. O material abordando os impactos da doença na gestação, parto e puerpério foi coletado entre março e julho de 2020. Nele incluímos, além dos posts e lives a que nos referimos acima, reportagens publicadas em sites de jornais brasileiros, artigos publicados em revistas científicas internacionais, bem como diretrizes e notas técnicas da OMS e do Ministério da Saúde (MS).

\section{Gestantes e puérperas como grupo de risco para Covid-19}

Covid-19 é uma doença nova, e as informações sobre fatores de risco para desenvolvimento de sua forma grave ainda são limitadas. Baseando-se em dados disponíveis no início da pandemia, a OMS classificou como grupos de risco pessoas acima de 65 anos e pessoas com doença preexistente (problemas cardíacos, hepáticos ou renais crônicos, hipertensão, diabetes, "obesidade grave", pessoas "imunocomprometidas", entre outros).

2 Este grupo foi criado no período da coleta de nosso material, em abril de 2020. Ver https://www. instagram.com/covid_and_preg_braz_group/. 
Diante do "terreno movediço" de evidências limitadas e instáveis acerca da Covid-19, a informação divulgada pela OMS em março de 2020 é ambígua ${ }^{3}$ no que se refere aos riscos para mulheres grávidas e puérperas, quando comparadas à população adulta de modo geral: "Data are limited, but at present there is no evidence that they are at higher risk of severe illness than the general population". ${ }^{4}$ Em consonância com essa informação, o Ministério da Saúde publicou no começo de abril uma nota técnica na qual afirmava que a Covid-19 não estava associada a maior risco de agravamento para mulheres grávidas e puérperas, tendo estas apresentado quadros clínicos e taxas de complicação semelhantes aos de adultos não gestantes (Brasil, 2020). Ainda assim, a partir de 9 de abril todas as gestantes e puérperas no Brasil passaram a ser consideradas como "grupo de risco" no caso da epidemia.

Segundo Carneiro (2020), essa inclusão levanta inúmeros debates na seara da vida reprodutiva das mulheres brasileiras. Um deles é sobre o melhor local para se dar à luz, pois a ideia do hospital como lugar seguro para o nascimento está sendo colocada em xeque. ${ }^{5}$ Esta questão, porém, é atravessada por recortes de classe e raça/cor, já que o parto domiciliar planejado exige recursos financeiros e condições geográficas/de localização favoráveis para a sua realização. Cabe acrescentar que além desses atravessamentos, a decisão sobre o nascimento no domicílio ou em casas de parto depende, antes, de critérios de "risco obstétrico", como problemas cardíacos, diabetes ou hipertensão. Outro debate

3 Lembramos que certo grau de ambiguidade e incerteza faz parte da linguagem científica. A cautela na divulgação de informações sobre a doença aparece em expressões como "não há evidências de que", que nos habituamos a ler nos últimos meses, não apenas sobre gravidez e nascimento.

4 Essa informação foi publicada no site da OMS na seção "perguntas e respostas sobre Covid-19, gravidez e parto", tendo sido atualizada em setembro de 2020. A nova orientação segue o padrão de classificação de risco aplicado à população em geral, que considera idade, peso e "doenças pré-existentes" como fatores de risco, passando a ter a seguinte redação: "Pregnant women or recently pregnant women who are older, overweight, and have pre-existing medical conditions such as hypertension and diabetes seem to have an increased risk of developing severe COVID-19. When pregnant women develop severe disease, they also seem to more often require care in intensive care units than non-pregnant women of reproductive age" (World Health Organization, 2020).

5 Davis-Floyd, Gutschow e Schwartz (2020) apresentam como gestantes nos EUA têm buscado partos fora do hospital - no domicílio ou em casas de parto - com medo da contaminação do ambiente hospitalar. 
diz respeito ao direito da presença de acompanhantes na hora do parto, frente à necessidade de diminuir o número de pessoas na sala de parto, visando reduzir riscos de contaminação. Esse ponto também foi discutido por Santana (2020) e Aleixo (2020), e por Tempesta (2020) no que tange especificamente à atuação das doulas.

Um terceiro debate levantado por Carneiro (2020), que nos interessa em especial, é como a própria noção de risco carreia ambivalências em relação à gestação, parto, e ao corpo feminino em si. Assim como pode representar proteção, a caracterização de grávidas e puérperas como grupo de risco pode implicar também violação dos direitos das mulheres a um pré-natal adequado e um parto digno e respeitoso. Assim, concordamos com Carneiro acerca da necessidade de refletirmos sobre os significados e sentidos de práticas e relações que se estabelecem e se fragilizam nesse contexto.

De fato, a ideia de risco associado à gravidez e ao nascimento é bastante difundida. Contudo, a leitura de gravidez e parto que vem sendo propugnada pelo $\mathrm{MH}$, foco deste artigo, busca distanciar-se desse risco-ameaça, da ideia de que "gravidez é doença" ou de que o parto vai dar errado. Essa leitura enfatiza tais momentos como normais na vida das mulheres, que devem ser vividos de forma simples e desdramatizada. Entretanto, essa visão guarda uma ambivalência importante: no ideário da humanização, gestantes e parturientes são, ao mesmo tempo, poderosas e vulneráveis. Mais adiante discutiremos como essa ambivalência opera no cenário atual. Antes, apresentaremos uma leitura antropológica sobre a construção do risco na gravidez e no nascimento, buscando diferenciá-lo da perspectiva biomédica. Em seguida, apontaremos os deslizamentos nas noções de risco associados à gravidez e nascimento no ideário que sustenta a proposta humanizadora. Depois, analisamos os argumentos usados no debate on-line.

\section{Aspectos gerais sobre risco na gravidez e no nascimento}

Gravidez e nascimento, enquanto processos que atravessam o corpo das mulheres e (re)produzem novos sujeitos, têm sido alvo de saberes especializados e do desenvolvimento de novas tecnologias, assim como tema de debates públicos que influenciam a construção de políticas de saúde. Esses processos também revelam, 
conforme observa Rezende (2011), como o corpo é cingido e vivenciado a partir de significados e práticas que variam entre as épocas e culturas, assim como entre diferentes segmentos sociais que coexistem em uma mesma sociedade.

Nas sociedades em que gravidez e nascimento foram medicalizados, os discursos de risco se intensificaram, tornando-se este um conceito-chave para gestão e prevenção de desfechos indesejáveis (Coxon et al., 2016; Lupton, 2012; Scamell; Alaszewski, 2012). Os discursos de risco nos modelos biomédicos de atenção ao pré-natal e parto operam dentro de uma abordagem técnico-científica (Chadwick; Foster, 2014). A avaliação objetiva dos riscos ampara-se no pressuposto de que eles podem ser conhecidos, quantificados e minimizados (Neves, 2008).

Nessas sociedades, pré-natal e parto passaram a ser gerenciados por especialistas e orientados para o monitoramento dos riscos, incluindo uma série de intervenções para identificar e corrigir complicações. Segundo Weir (2006), as "técnicas de risco" foram associadas à gravidez e ao nascimento com a intenção de reduzir a mortalidade perinatal, norteando o gerenciamento de cuidados pré-natais. A partir de uma orientação preventiva e calculista do risco epidemiológico, essas avaliações foram padronizadas, passaram a ser rotina na prática clínica e impregnaram os cuidados com as gravidezes. Assim, visando garantir o nascimento seguro de bebês saudáveis, desde o início do pré-natal, as mulheres são classificadas de acordo com categorias de risco. No Brasil, as grávidas são divididas em dois grupos: alto risco e baixo risco (ou "risco habitual") - nunca "sem risco".

A sociologia e a antropologia vêm contribuindo para a relativização do conceito de risco nas sociedades ocidentais contemporâneas. Essa relativização é fundamental para a compreensão de que - apesar da centralidade do risco biomédico - as construções associadas a esse conceito são complexas, pois variam entre os diferentes atores envolvidos e de acordo com contextos socioculturais e históricos específicos. Embora haja diferenças entre as abordagens cultural e sociológica, ambas apontam para a tensão entre um conhecimento perito que "determina" os riscos e uma população leiga que os "percebe". Apontam também para os limites das avaliações técnicas/quantitativas que pressupõem que as sociedades compartilham consensos sobre os riscos (Guivant, 1998). Essas avaliações são criticadas, sobretudo, por simplificarem os contextos relacionados aos riscos. 
$\mathrm{Na}$ abordagem cultural, as categorias risco/perigo são analisadas a partir de sua natureza coletiva, seu caráter simbólico e moral, e dos rituais que orientam comportamentos nessas situações (Neves, 2008). Esses sistemas conceituais devem ser compreendidos em relação à estrutura classificatória de cada cultura, visto que suas cargas simbólicas revelam assimetrias e hierarquias que regem a vida social. Assim, cada cultura estabelece os estados portadores de risco, cuja definição associa-se às exigências morais da sociedade, e não necessariamente ao caráter objetivo do perigo (Neves, 2008). A abordagem cultural está interessada no perigo como mecanismo para policiar as fronteiras simbólicas, isto é, como um meio de manter a ordem e a coesão social (Chadwick; Foster, 2014).

A categoria risco, enquanto construção coletiva de ordenamento da vida social, atua no âmbito da estrutura do pensamento e das ações sociais, orientando percepções, julgamentos e ações na vida cotidiana (Neves, 2008). Classificações de risco carregam valores definidos pelo entorno social que servem para "qualificar" acontecimentos, coisas e pessoas. Ao rotular indivíduos ou comportamentos, por exemplo, elas acabam por "[situá-los] num sistema hierarquizado em conformidade com a apreciação valorativa vigente" (Neves, 2008 , p. 36). Seguindo nessa perspectiva, Guivant $(1998$, p. 5) aponta que "na seleção dos riscos relevantes, nem sempre a evidência científica teria o papel esclarecedor, pelo fato de que a escolha responderia a fatores sociais e culturais, e não naturais". Isto é, essa seleção é parte de um processo sociocultural que acontece de acordo com o papel que os riscos assumem no reforço da solidariedade social. Assim, "[ao] se considerar que os riscos são percebidos e administrados de acordo com princípios inerentes que reforçam formas particulares de organização social, deixa de ser possível tratar os riscos de forma neutra, com ferramentas metodológicas quantitativas" (Guivant, 1998, p. 6).

\section{Deslizamentos das noções de risco e o movimento de humanização}

Que formas particulares de organização social são reforçadas no caso do risco associado à gravidez e ao parto? Na constituição da obstetrícia científica, a concepção desses acontecimentos como eminentemente perigosos integrou um 
processo mais amplo de controle do corpo da mulher e da reprodução (Martins, 2004), sendo a mulher vista como naturalmente fraca e vulnerável (quando comparada ao homem). Transformações socioculturais a partir de meados do século XX, influenciadas principalmente pelo feminismo de "segunda onda", impactaram de forma crucial a relação entre a mulher e a medicina. A visão médica da gravidez, parto e puerpério passou a ser objeto de crítica, sendo paulatinamente construída outra visão desses momentos, na qual busca-se transformar a noção de risco a eles associados. ${ }^{6}$ Uma nova construção que enfatiza o corpo como relacional, consciente e capaz, e não como fonte de potenciais perigos ou como receptores passivos de tecnologias médicas para reduzir o risco (Chadwick; Foster, 2014). Essa crítica, também vinda do interior da própria obstetrícia, desenvolveu-se nas últimas décadas do século passado, desembocando no movimento pela "humanização do parto" (Russo et al., 2019).

De modo muito breve poderíamos caracterizar o parto humanizado por seu distanciamento da "cena de parto" hospitalar convencional, na qual a gestante fica deitada, recebendo soro, sendo atendida por um conjunto de profissionais treinados para realizar intervenções danosas, como episiotomia, manobra de Kristeler e uso indiscriminado da ocitocina sintética. O MH abarca um conjunto de valores e propostas que se opõem às formas "medicalizadas" e "intervencionistas" de assistência ao parto, visando sua transformação (Silva; Russo, 2019). A "humanização do parto", apesar de seu caráter múltiplo e polissêmico e de apresentar vertentes com diferentes abordagens, ${ }^{7}$ busca, em linhas gerais, promover uma "valorização de modos de intervenção mais 'soft' e 'flexíveis"' (Robles, 2015, p. 144), e implementar comportamentos e práticas que promovam um acolhimento respeitoso à gestante (incluindo a oferta de informações, o consentimento da mulher acerca das intervenções e o respeito à sua autonomia). Trata-se portanto de "desmedicalizar" o parto - uma desmedicalização

6 Embora vários de seus pressupostos façam parte das recomendações da OMS e do MS, ainda há uma resistência do establishment obstétrico brasileiro a abandonar práticas mais pesadamente medicalizantes - incluindo a cesárea eletiva - tendendo a ver o parto como uma ação realizada pelo médico (Nakano; Bonan; Teixeira, 2017).

7 Segundo Tornquist (2004), o MH apresenta duas principais correntes de pensamento, a "alternativa" e a "biomédica", que se influenciam mutuamente a partir de uma "negociação de significados" na qual a categoria "natureza" é ponto de acordo. 
sui generis, pois calcada na medicina baseada em evidências (Russo et al., 2019). O ideário que sustenta a proposta humanizadora, em sua forma mais suave ou mais radical, também enfatiza o protagonismo da mulher no momento do parto.

Entretanto, ao mesmo tempo que gravidez e parto são descritos como acontecimentos naturais (devendo ser vividos de forma natural), também são considerados eventos de enorme relevância moral e emocional. Momentos especiais na vida das mulheres, através dos quais elas podem vivenciar experiências inesquecíveis e transformadoras. Seriam, portanto, muito delicados. A intensidade e delicadeza (física-moral-emocional) desses eventos faz com que eles se transformem, assim, em situações de vulnerabilidade e perigo potencial. A ambivalência se complexifica quando se contrapõe a teoria e a prática da obstetrícia biomédica ao "saber" inscrito nos corpos das mulheres (que confere a elas um poder a ser respeitado).

Para o $\mathrm{MH}$, gravidez e parto devem ser vistos como eventos que, embora possam requerer alguma assistência, geralmente se desenrolam sem maiores problemas. Isto é, apesar de comportar algum risco (de complicações, e possível morte), não devem ser definidos por isso. Pelo contrário, devem ser conceituados como uma experiência que, se bem vivida, pode ser prazerosa e feliz. O grande perigo estaria associado justamente ao excesso de intervenções, bem como aos maus-tratos e negligência na assistência (Diniz, 2009).

\section{O risco no/do corpo}

A inclusão das grávidas e puérperas nos grupos de risco foi recebida com certo entusiasmo por uma parcela das ativistas do MH. "Finalmente! Precisamos proteger as gestante e puérperas. O binômio mãe-bebê", afirmou uma médica obstetra em seus perfis no Facebook e Instagram no dia 11 de abril, ao anunciar esse fato para seus seguidores.

Diferente da classificação realizada rotineiramente durante o pré-natal - no qual as mulheres são categorizadas de acordo com a presença de "fatores de risco" para o desenvolvimento de complicações na gestação e no parto a caracterização de todas as grávidas e puérperas como grupo de risco parece levar em consideração não um risco maior decorrente de fatores preexistentes 
ou uma suscetibilidade maior de contrair o vírus, mas um risco aumentado de desenvolverem complicações caso sejam infectadas pelo vírus, conforme explicou a médica em uma live no dia 16 de abril:

A gente não sabe exatamente a magnitude dos danos que podem acontecer durante a gravidez. [...] Hoje em dia a gente sabe que a grávida pode pegar Covid19 como qualquer pessoa, mas em alguns estudos começam a aparecer que talvez lá pelo final da gravidez, comecinho do puerpério, pode ser que ela esteja mais suscetível a complicações. E isso, assim, se a gente for pensar é bem lógico: a imunidade da grávida está mais diminuída, a grávida tem modificações no organismo do ponto de vista respiratório, do ponto de vista cardíaco e do ponto de vista da coagulação, então ela pode estar mais suscetível. Inclusive a gente já viu isso com o H1N1, a gente já viu isso no cenário da Sars e da Mers. A gente vê isso com qualquer virose e eu não vejo por que seria tão diferente. Então, existe essa preocupação que a gente não pode afastar.

Os argumentos, portanto, referem-se principalmente a experiências anteriores com doenças respiratórias provocadas por outros coronavírus (Sars e Mers) além da influenza A (H1N1), sendo reconhecida a falta de evidências específicas para a Covid-19. ${ }^{8}$ Tais argumentos salientam as alterações fisiológicas que acometem grávidas e puérperas deixando-as mais suscetíveis a infecções respiratórias e desenvolvimento de pneumonia grave, principalmente se tiverem doenças crônicas ou apresentarem complicações durante a gravidez - o que, nesse caso, representaria uma "soma de fatores de risco".

Nos últimos anos o $\mathrm{MH}$ vem se pautando em evidências científicas recentes para transformar o modelo de assistência obstétrica, de modo que este seja centrado na "experiência positiva" das mulheres. Contudo, quando se trata de Covid-19, apesar do volume de estudos realizados, as evidências produzidas

8 O GBECG publicou uma nota, em abril de 2020, na qual buscava chamar atenção da comunidade médica internacional para "os dados" de países em desenvolvimento, como o Brasil, que naquela época já estavam "levantando a possibilidade do aumento no risco de mortes maternas por Covid-19" (Amorim; Takemoto; Fonseca, 2020, p. 298, tradução nossa), conforme abordaremos adiante. Nessa nota, as autoras citam as "adaptações fisiológicas" da gravidez, parto e pós-parto como "fatores de risco" para agravamento da doença e morte. 
ainda são pouco ou nada conclusivas, apresentando dados que mudam a todo momento a compreensão sobre o vírus, e que não são capazes de explicar os efeitos da epidemia nos diferentes contextos ou grupos populacionais.

Um exemplo dessa "instabilidade científica" refere-se à possibilidade de transmissão vertical, isto é, da mulher para o feto/bebê durante a gravidez ou no parto. Antes do início da pandemia, quando o problema ainda estava circunscrito à China continental, algumas publicações diziam não haver "evidências confiáveis" de que o vírus pudesse ser transmitido (Chen et al., 2020; Qiao, 2020). Mas, como a suspeita é suficiente para justificar mais atenção e escrutínio, desde então começaram a surgir novas evidências, baseadas em estudos de pequenos números de casos, sugerindo que a transmissão pode acontecer.

A pandemia também vem causando problemas na compreensão de evidências já consolidadas. Esse é o caso dos estudos sobre o apoio contínuo oferecido por doulas (como fator que favorece desfechos positivos) que entraram em choque com novas evidências que apontam o distanciamento social como uma das poucas medidas capazes de reduzir a propagação do novo coronavírus, conforme discutiremos a seguir.

\section{Contágio e redefinição da cena do parto}

A Covid-19 atualiza, em certa medida, o medo difuso associado à experiência das antigas pestes e a velha noção de contágio, como algo que "passaria de uma coisa para outra diretamente, de pele a pele; ou indiretamente, mediado por objetos; também poderia ocorrer à distância sem mediação de nenhum objeto" (Czeresnia, 1997, p. 50). O perigo de contágio que marca a atual epidemia - perigo não apenas para mulheres que buscam atendimento nos serviços de saúde, mas também para os profissionais que as atendem - aponta para algumas transformações na gestação, parto e pós-parto.

As diretrizes e notas técnicas divulgadas por integrantes do $\mathrm{MH}$ recomendam que durante a gravidez as mulheres tomem as mesmas precauções que outras pessoas para evitar a infecção (lavar as mãos, evitar tocar a face, manter distanciamento social e praticar higiene respiratória), além de continuar comparecendo às consultas pré-natais. Entretanto, diante da necessidade de readequação dos serviços de saúde para atendimento prioritário às pessoas 
com Covid-19, com consequente fechamento de alguns serviços de maternidade (Médico..., 2020; Prefeitura Municipal de Curitiba, 2020), as ativistas vêm clamando para que a assistência pré-natal não seja comprometida durante a pandemia. As profissionais de saúde afirmam categoricamente que atitudes precisam ser tomadas para proteger o "binômio mãe-bebê" e que os cuidados devem ser rigorosos e contínuos, independentemente do histórico clínico das pacientes, pois se trata de um "grupo vulnerável" e que necessitaria, portanto, de cuidados adicionais. $\mathrm{O}$ argumento é que, mesmo se no futuro tais cuidados se mostrarem exagerados, ou mesmo que novas informações levem à modificação desses cuidados, as decisões precisam ser tomadas com urgência.

Mas se, por um lado, o "pré-natal mínimo" precisa ser garantido para não "deixar passar mulheres cuja condição pode se agravar ao longo da gravidez", por outro, a rigor, a exposição da mulher a ambientes potencialmente contaminantes, como postos de saúde e hospitais, aumenta o risco de contágio. Ou seja, o contato com serviços de saúde durante o pré-natal e, sobretudo, no parto, passa a ser objeto de maior cuidado e atenção. Esse risco de contágio impactou na transformação da cena do parto, fato que afeta particularmente profissionais e as mulheres adeptas do parto humanizado.

Como mencionado anteriormente, o direito de estar acompanhada durante o parto, seja por familiares ou por uma doula, tem sido tema de debate durante a pandemia e motivo para dissenso entre ativistas do $\mathrm{MH}$. A recomendação para limitar o número de pessoas circulando nos hospitais/maternidades está presente em diversas diretrizes relativas à assistência ao parto. Assim, só seria permitido um acompanhante por mulher, que seja de seu convívio, não pertença aos grupos de risco e não apresente sintomas gripais, sendo vedado o rodízio de pessoas. Para algumas ativistas, essa restrição é necessária nesse momento para reduzir a disseminação do vírus, isto é, como "um direito coletivo que vai se sobrepor ao direito individual" da mulher que pare. Contudo, para outras, o direito das mulheres a uma assistência digna e respeitosa está sendo "relativizado", já que a Lei do Acompanhante segue sendo descumprida em muitos hospitais/maternidade e a limitação de pessoas não seria aplicável a outros profissionais, como anestesistas e pediatras, por exemplo.

Outra recomendação é para que toda a equipe dentro da unidade obstétrica e as mulheres com suspeita ou diagnóstico confirmado da Covid-19 
usem máscaras e outros equipamentos de proteção durante o parto. Entretanto, conforme relatou uma enfermeira obstetra em uma live no Instagram em 23 de abril:

No trabalho de parto, principalmente no expulsivo, é difícil a gestante continuar usando a máscara. É um momento de desorganização, vamos dizer assim, desses padrões de controle do risco de infecção [...]. Pessoas confirmadas ou suspeitas, seja sintomática ou assintomática, podem transmitir a partir da emissão de gotículas [...]. Imagina, então, uma pessoa que está no expulsivo, que tá empurrando, fazendo força, que tá gritando, vocalizando, a chance de que existam gotículas no ambiente nesse momento é bastante considerável [...]. A ideia por trás dessa interdição [do contato pele-a-pele, segundo a Sociedade Brasileira de Pediatria] é porque esse bebê, em tese, saudável, iria para o pele a pele em um momento em que haveria uma chance bastante considerável de gotículas presentes pela própria dinâmica do expulsivo.

Desconstruir/desorganizar o setting hospitalar tradicional onde se desenrolava o parto está no âmago do modo de parir proposto pelo MH. Este setting, com tudo que implica do ponto de vista de paramentos, instrumentos e isolamentos, deve ser abandonado em nome da "normalidade" do parto e do protagonismo da parturiente.

Ao contrário do setting tradicional, uma sala de parto humanizado deve ser o mais próxima possível de um quarto qualquer. A parturiente pode escolher ficar sentada em almofadas, deitada na cama, de pé deambulando. Pode dar à luz no quarto ou na banheira, na posição que for mais cômoda para si. O contato entre ela e as pessoas que a acompanham não deve ser mediado por aparatos ou vestimentas. Pelo contrário, proximidade, contato corporal e o toque das mãos são valorizados. Como se costuma dizer, o "pele a pele". Igualmente, os fluidos devem circular livremente. Líquido amniótico, sangue, lágrimas, urina e fezes - não há uma preocupação especial em separar os fluidos ou neutralizá-los. A preocupação higiênica não deve ser uma barreira para a vivência integral desse momento de ímpar relevância subjetiva. Além disso, a placenta destaca-se como símbolo da conexão mãe-bebê, devendo a mulher decidir se vai "plantá-la", consumi-la em cápsulas ou in natura, ou utilizá-la como "carimbo" em gravuras. A corporalidade valorizada pelo parto humanizado 
implica necessariamente contato, mistura, cruzamentos e embaralhamentos com/entre substâncias e pessoas.

Como observamos acima, parir durante a pandemia, enquanto "momento de desorganização dos padrões de controle da infecção", faz com que certos aspectos já consolidados na humanização sejam novamente debatidos e, em alguma medida, modificados. Enquanto o alojamento conjunto e a amamentação permanecem nas recomendações como práticas a serem mantidas e estimuladas, mesmo para mulheres com suspeita ou diagnóstico confirmado da Covid-19, o contato pele a pele seria contraindicado nesses casos. A lógica dessa interdição é que quanto maior a proximidade e mais tempo se passar perto de uma pessoa infectada, mesmo que assintomática, maior o risco de contágio; e a prática do pele a pele é, por definição, contato íntimo, imediato e prolongado com o bebê (momento denominado golden hour). Nesse sentido, a recomendação dos profissionais humanizados para essa prática, por exemplo, é realizar, após o nascimento, uma higienização com clorexidina das partes do corpo da mulher que terá contato com o bebê (para remover as "gotículas") e colocar a máscara antes de pegá-lo no colo. Além dessas mudanças, o parto na água, considerado um recurso não farmacológico importante para alívio da dor, está sendo desaconselhado, e a placenta, que representava a "árvore da vida" (Menezes, 2019), agora está sendo considerada resíduo potencialmente infectante, devendo ser imediatamente descartada.

Assim, o risco de contágio parece afetar grande parte do que caracteriza um parto humanizado. O contato corporal, a mistura de fluidos, o desenrolar "desorganizado" devem ser controlados quando o Outro representa fonte de perigo. Porém, conforme aponta Czeresnia (1997, p. 9), "o sentimento de ameaça, que está na base dessa experiência, convive com a circunstância de que a relação com o outro é necessária ou mesmo primordial, o que remete a uma condição paradoxal".

\section{O que ou quem está em risco?}

A questão da mortalidade materna - considerada pelos especialistas desse campo como um indicador importante e politicamente poderoso (Storeng; Béhague, 2017) - também foi alvo das denúncias que encontramos nos posts. 
Na época em que houve a inclusão, o Brasil contabilizava três casos de morte materna em decorrência da Covid-19, em um total aproximado de 1.100 mortes. Atualmente, em agosto de 2020, seguindo uma evolução catastrófica no (des)controle da epidemia, o país contabiliza mais de 200 mortes maternas em um total de mais de 100 mil mortos. Diante da falta de dados oficiais do MS e da subnotificação de óbitos por Covid-19 no país, essas mortes estão sendo compiladas e divulgadas pelo $\mathrm{MH} .{ }^{9}$ Uma estatística amplamente divulgada é que entre dez mortes maternas por Covid-19 ocorridas no mundo, oito são de brasileiras (Lisauskas, 2020). Aqui seria necessário discutir a mortalidade materna tout court no país, que já era alta antes da pandemia. Também é necessário perguntar: quem são as mulheres que figuram nessa alta taxa de mortalidade?

Com a evolução da epidemia, ficou evidente que as populações mais atingidas - do ponto de vista da gravidade da doença e da mortalidade - são os grupos socialmente vulneráveis e marginalizados, como negros e pobres que vivem tanto nas periferias quanto em áreas distantes dos grandes centros urbanos, além das populações indígenas, vítimas de verdadeiro genocídio. É possível imaginar um cruzamento dessa estatística com a mortalidade materna por Covid-19 - ou seja, as mulheres que estão apresentando quadro agravado da doença, com alta probabilidade de morte, possivelmente pertencem a esses grupos de risco socialmente (e não medicamente) definidos. Assim como o recorte de classe e raça/cor, o desmonte do SUS nos últimos anos, como sabemos, também vem desempenhando um papel primordial nesses resultados. ${ }^{10}$

Desse ponto de vista, o "entusiasmo" pela inclusão de todas as gestantes e puérperas nos grupos de risco deve ser visto com cautela. Isso porque os argumentos utilizados, ao enfatizarem parâmetros biomédicos, apesar de estarem baseados em observações médicas, deixam de lado gritantes evidências sociológicas. É claro que não queremos negar que transformações corporais

9 Esse trabalho está sendo realizado, principalmente, pelo GBECG. O grupo reúne e analisa as informações sobre óbitos maternos a partir de reportagens e de relatos de profissionais da assistência, e publica notas de pesquisa em periódicos nacionais e internacionais.

10 Esses atravessamentos foram reconhecidos pelo MH a partir da nota publicada pelo GBECG na revista Clinical Infectious Diseases. Nessa nota de pesquisa, Santos et al. (2020) abordam o impacto desproporcional da doença entre mulheres negras no Brasil. 
acontecem durante a gravidez, no parto e no pós-parto, tampouco negamos os desafios impostos pela nova doença, que instala um contexto extraordinário afetando particularmente grávidas, parturientes e puérperas. Queremos chamar atenção para o modo como a expressão "fator de risco" é utilizada dentro da lógica biomédica, que ressalta uma espécie de "vulnerabilidade essencial" dessas mulheres, ofuscando as desigualdades estruturais que marcam os desfechos perinatais no país.

Gostaríamos de encerrar este artigo tecendo reflexões sobre algumas tensões que se estabelecem nesse contexto. A caracterização de grávidas e puérperas como grupo de risco representa uma estratégia política importante, que visa chamar atenção para a "saúde materna", assim como assegurar o cumprimento de direitos para grávidas e puérperas (de cuidados de saúde e de afastamento do trabalho, por exemplo). Contudo, o preço a se pagar pode ser a reafirmação da "vulnerabilidade" dessas mulheres, independentemente das diferenças que possam existir entre elas. Ademais, considerando que circunstâncias "de risco" podem justificar mais intervenções na cena do parto, é importante que nos perguntemos: quais serão os impactos nas práticas de assistência e nas subjetividades de quem está "mais em risco"? Seriam essas transformações na cena (com a possível perda de protagonismo, e consequente fragilização do poder da parturiente em comandar o próprio parto) uma nova "volta do parafuso da medicalização"? Ainda, quais serão os impactos na disputa entre as diferentes perspectivas obstétricas e entre os diferentes profissionais envolvidos nesse novo cenário? Afinal, se a equipe deve ser reduzida ao mínimo possível, quem se mostrará indispensável?

Por fim, cabe dizer que este artigo foi escrito nos meses iniciais da pandemia e, nesse período, tivemos que lidar com informações que foram (e ainda estão) se transformando no decorrer do tempo. Nossa curiosidade foi instigada pela pressão exercida por representantes do $\mathrm{MH}$ no sentido de incluir gestantes e puérperas no grupo de risco. Buscamos compreender os argumentos favoráveis a essa inclusão e as propostas de mudança na cena do parto induzidas pelas noções de risco que a pandemia evoca. Esperamos com isso contribuir para aprofundar as reflexões em torno desse período peculiar da vida de tantas mulheres, que envolve políticas de Estado, profissionais diversos e movimentos da sociedade civil num complexo emaranhado de desafios, lutas e alianças que a pandemia agora põe à prova. 


\section{Referências}

ALEIXO, M. O acompanhamento à gestante em tempos de Covid-19: notas para o debate. In: GRUNVALD, V. et al. (ed.). antropoLÓGICAS EPIDÊMICAS, [s. l.], 1 jun. 2020. Disponível em: https://www.antropologicas-epidemicas.com.br/post/o-acompanhamento-\%C3\%A0-gestante-em-tempos-de-covid-19-notas-para-o-debate. Acesso em: 10 jun. 2020.

AMORIM, M.; TAKEMOTO, M.; FONSECA, E. Maternal deaths with coronavirus disease 2019: a different outcome from low- to middle-resource countries?. American Journal of Obstetrics \& Gynecology, New York, v. 223, n. 2, p. 289-299, 2020.

BRASIL. Ministério da Saúde. Secretaria de Atenção Primária à Saúde. Departamento de Ações Programáticas Estratégicas. Coordenação-Geral de Ciclos da Vida. Coordenação da Saúde da Mulher. Nota técnica nº 12/2020-COSMU/CGCIVI/DAPES/ SAPS/MS. Infecção COVID-19 e os riscos às mulheres no ciclo gravídico-puerperal. Brasília: MS, 18 abr. 2020.

CARNEIRO, R. Cenas de parto e políticas do corpo. Rio de Janeiro: Ed. Fiocruz, 2015.

CARNEIRO, R. Gestar e parir em tempos de COVID-19: uma tragédia anunciada?. Boletim Cientistas Sociais e o Coronavírus, São Paulo, n. 29, 28 abr. 2020. Disponível em: https://anpocs.org/index.php/publicacoes-sp-2056165036/boletim-cientistas-sociais/2343-boletim-n-29-cientistas-sociais-e-o-coronavirus. Acesso em: 10 jun. 2020.

CHADWICK, R.; FOSTER, D. Negotiating risky bodies: childbirth and constructions of risk. Health, Risk \& Society, Abingdon, v. 16, n. 1, p. 68-83, 2014.

CHEN, H. et al. Clinical characteristics and intrauterine vertical transmission potential of COVID-19 infection in nine pregnant women: a retrospective review of medical records. The Lancet, [s. l.], v. 395, p. 710-711, 2020.

COXON, K. et al. Editorial: reconceptualising risk in childbirth. Midwifery, Oxford, v. 38, p. 1-5, 2016.

CZERESNIA, D. Do contágio à transmissão: ciência e cultura na gênese do conhecimento epidemiológico. Rio de Janeiro: Ed. Fiocruz, 1997.

DAVIS-FLOYD, R.; GUTSCHOW, K.; SCHWARTZ, D. A. Pregnancy, birth and the COVID-19 pandemic in the United States. Medical Anthropology, Abingdon, v. 39, n. 5, p. 413-427, 2020.

DINIZ, C. S. Humanização da assistência ao parto no Brasil: os muitos sentidos de um movimento. Ciência \& Saúde Coletiva, Rio de Janeiro, v. 10, n. 3, p. 627-637, 2005. 
DINIZ, C. S. Gênero, saúde materna e o paradoxo perinatal. Revista Brasileira de Crescimento e Desenvolvimento Humano, São Paulo, v. 19, n. 2, p. 313-326, 2009.

GUIVANT, J. A trajetória das análises de risco: da periferia ao centro da teoria social. BIB: Revista Brasileira de Informação Bibliográfica em Ciências Sociais, São Paulo, n. 46, p. 3-38, 1998.

JONES, R. Apresentação à nova edição brasileira. In: BALASKAS, J. Parto ativo: guia prático para o parto natural. São Paulo: Editora Aquariana/Ground, 2015. p. 13-18.

LISAUSKAS, R. Oito em cada dez gestantes e puérperas que morreram no mundo eram brasileiras. Estadão, São Paulo, 14 jul. 2020. Disponível em: https://emais.estadao.com.br/blogs/ser-mae/oito-em-cada-dez-gestantes-e-puerperas-que-morreram-de-coronavirus-no-mundo-eram-brasileiras/. Acesso em: 15 jul. 2020.

LUPTON, D. 'Precious cargo': foetal subjects, risk and reproductive citizenship. Critical Public Health, Abingdon, v. 22, n. 3, p. 329-340, 2012.

MARTINS, A. Visões do feminino: a medicina da mulher nos séculos XIX e XX. Rio de Janeiro: Ed. Fiocruz, 2004.

MÉDICO denuncia fechamento de maternidade em Jaboatão; gestantes chegam e ficam sem atendimento. In: TV JORNAL. Recife: JCPM, 10 maio 2020. Disponível em: https://vjornal.ne10.uol.com.br/noticia/2020/05/10/medico-denuncia-fechamento-de-maternidade-em-jaboatao-gestantes-chegam-e-ficam-sem-atendimento-188313. Acesso em: 10 ago. 2020.

MENEZES, R. “Usei o 'carimbo' da placenta do Valentin para fazer um quadro da árvore da vida”, diz Carol Dantas. Crescer, Rio de Janeiro, 1 out. 2019. Disponível em: https://revistacrescer.globo.com/Pais-famosos/noticia/2019/10/usei-o-carimbo-da-placenta-d-valentin-para-fazer-um-quadro-da-arvore-da-vida-diz-carol-dantas. html. Acesso em: 10 jun. 2020.

NAKANO, A.; BONAN, C.; TEIXEIRA, L. O trabalho de parto do obstetra: estilo de pensamento e normalização do "parto cesáreo" entre obstetras. Physis, Rio de Janeiro, v. 27, n. 3, p. 415-432, 2017.

NEVES, E. Antropologia e ciência: uma etnografia do fazer científico na era do risco. São Luís: Edufma, 2008.

PREFEITURA MUNICIPAL DE CURITIBA. Maternidade Bairro Novo transfere partos e reforça rede de combate à covid-19. Curitiba: Prefeitura Municipal de Curitiba, 27 mar. 2020. Disponível em: https://www.curitiba.pr.gov.br/noticias/maternidade-bairro-novo-transfere-partos-e-reforca-rede-de-combate-a-covid-19/55456. Acesso em: 10 ago. 2020. 
QIAO, J. What are the risks of COVID-19 infection in pregnant women?. The Lancet, [s. l.], v. 395, p. 760-762, 2020.

REZENDE, C. Um estado emotivo: representação da gravidez na mídia. Cadernos Pagu, Campinas, n. 36, p. 315-344, 2011.

ROBLES, A. Da gravidez de "risco" às "maternidades de risco": Biopolítica e regulações sanitárias nas experiências de mulheres de camadas populares de Recife. Physis, Rio de Janeiro, v. 25, n. 1, p. 139-169, 2015.

RUSSO, J. et al. Escalando vulcões: a releitura da dor no parto humanizado. Mana, Rio de Janeiro, v. 25, n. 2, p. 519-550, 2019.

SANTANA, N. "Medo do desconhecido" - atenção às gestantes, parturientes e puérperas no contexto da COVID-19. Boletim Cientistas Sociais e o Coronavírus, São Paulo, n. 29, 28 abr. 2020. Disponível em: https://anpocs.org/index.php/publicacoes-sp-2056165036/boletim-cientistas-sociais/2343-boletim-n-29-cientistas-sociais-e-o-coronavirus. Acesso em: 10 jun. 2020.

SANTOS, D. et al. Disproportionate impact of Coronavirus Disease 2019 (COVID19) among pregnant and postpartum black women in Brazil through structural racism lens. Clinical Infectious Diseases, [s. l.], 2020. DOI: https://doi.org/10.1093/cid/ ciaa1066.

SCAMELL, M; ALASZEWSKI, A. Fateful moments and the categorisation of risk: midwifery practice and the ever-narrowing window of normality during childbirth. Health, Risk \& Society, Abingdon, v. 14, n. 2, p. 207-221, 2012.

SILVA, F.; RUSSO, J. “A porta da transformação só abre pelo lado de dentro": notas etnográficas sobre o processo da (trans)formação de si em cursos de capacitação de doulas. Cadernos de Gênero e Diversidade, Salvador, v. 5, n. 4, p. 162-180, 2019.

STORENG, K.; BÉHAGUE, D. “Guilty until proven innocent": the contested use of maternal mortality indicators in global health. Critical Public Health, Abingdon, v. 27, n. 2, p. 163-176, 2017.

TEMPESTA, G. Como apoiar o início da vida em tempos de morte? Pensando sobre o ofício das doulas durante a pandemia. Boletim Cientistas Sociais e o Coronavírus, São Paulo, n. 49, 27 maio 2020. Disponível em: https://anpocs.org/index.php/publicacoes-sp-2056165036/boletim-cientistas-sociais/2371-boletim-n-49-cientistas-sociais-e-o-coronavirus. Acesso em: 10 jun. 2020.

TORNQUIST, C. Parto e poder: o movimento pela humanização do parto no Brasil. 2004. Tese (Doutorado em Antropologia Social) - Centro de Filosofia e Ciências Humanas, Universidade Federal de Santa Catarina, Florianópolis, 2004. 
WEIR, L. Pregnancy, risk, and biopolitics: on the threshold of the living subject. New York: Routledge, 2006.

WORLD HEALTH ORGANIZATION. Coronavirus disease (COVID-19): pregnancy and childbirth. [S. l.]: WHO, 2 Sept. 2020. Disponível em: https://www.who.int/emergencies/diseases/novel-coronavirus-2019/question-and-answers-hub/q-a-detail/q-a-on-covid-19-pregnancy-and-childbirth. Acesso em: 8 set. 2020.

Recebido: 31/08/2020 Aceito: 20/01/2021 | Received: 8/31/2020 Accepted: 1/20/2021 